\title{
Rire à la Renaissance, édité par Marie Madeleine Fontaine
}

\section{Michele Mastroianni}

\section{Q OpenEdition \\ 1 Journals}

\section{Edizione digitale}

URL: http://journals.openedition.org/studifrancesi/5593

DOI: $10.4000 /$ studifrancesi.5593

ISSN: 2421-5856

\section{Editore}

Rosenberg \& Sellier

\section{Edizione cartacea}

Data di pubblicazione: 1 septembre 2011

Paginazione: 399-400

ISSN: 0039-2944

\section{Notizia bibliografica digitale}

Michele Mastroianni, «Rire à la Renaissance, édité par Marie Madeleine Fontaine», Studi Francesi

[Online], 164 (LV | II) | 2011, online dal 30 novembre 2015, consultato il 13 janvier 2021. URL: http:// journals.openedition.org/studifrancesi/5593 ; DOI: https://doi.org/10.4000/studifrancesi.5593

Questo documento è stato generato automaticamente il 13 janvier 2021.

\section{(c) (i) (9)}

Studi Francesi è distribuita con Licenza Creative Commons Attribuzione - Non commerciale - Non opere derivate 4.0 Internazionale. 


\title{
Rire à la Renaissance, édité par Marie Madeleine Fontaine
}

\author{
Michele Mastroianni
}

\section{NOTIZIA}

Rire à la Renaissance, "Colloque international de Lille, Université Charles de Gaulle-Lille 3, 6-8 novembre 2003», édité par Marie Madeleine fonTAINE, Genève, Droz, 2010 («Travaux d'Humanisme et Renaissance», CDLXIX), 540 pp.

1 Come sottolinea la curatrice, il Colloque di Lille non si è proposto tanto di teorizzare $\mathrm{i}$ rires del Rinascimento, quanto di dimostrare che nel Cinquecento «ridere era un atto pubblico infuso in tutte le altre manifestazioni della società e che questo rire è ancora largamente comprensibile oggi». In quest'ottica, storici della letteratura, musicologi e storici dell'arte hanno indagato opere, circostanze sociali, comportamenti privati e collettivi, percorrendo i grandi autori ma anche i frutti dell'érudition facétieuse, le parodie, le testimonianze sul ridere in documenti ufficiali o di vita corrente. Così, abbiamo interventi sul principe del rire, Rabelais, di cui si esaminano i testi, ma anche la ricezione presso autori della letteratura lontani dal Cinquecento, come Balzac e Nodier; interventi su Montaigne o sul primo trattato sul rire, quello di Laurent Joubert; come pure vengono analizzate raccolte di indovinelli, relazioni di viaggi, raccolte di testi per la mise en musique sia dotta che popolare; viene inoltre affrontato, sul piano dell'iconografia, il problema della rappresentazione pittorica del riso.

2 I contributi pubblicati sono i seguenti: Lakis PRoGuidIs, L'appétit existentiel (pp. 11-18); Frank DOBBINS, Le traitement musical du rire à la Renaissance (pp. 23-39); Anne-Hélène KLINGER-DOLLÉ, Le rire inscrit dans le texte. Interprétations balzaciennes du rire rabelaisien (pp. 53-71); Hope GLIDDEN, Logique de l'absurde et vie quotidienne selon Tabourot (pp. 73-83); Marine MOLINS, Les lardons de Panurge (pp. 85-92); Max ENGAMMARE, Gens qui rient, Jean qui pleure. Rires de Genevois surpris dans les Registres du Consistoire au temps de Calvin (pp. 93-106); Henri vanhulst, La Fricassée de Jean Crespel, une cuvre pour rire? (pp. 109-121); 
Mireille HUCHON, Les rires de Rabelais (pp. 123-139); Rosanna GORRIS-CAMOS, «Penser le rire et rire de cœur». Le "Traité du ris" de Laurent Joubert, médecin de l'âme et du cœur (pp. 141-161); Michèle-Caroline HECK, Rire et cris. De la difficulté et de l'enjeu de leur représentation en peinture (pp. 163-179); Michel JOURDE, Rire des bêtes: l'ivresse du perroquet (pp. 181-193); Frank LESTRINGANT, Rire en Sardaigne et ailleurs. Le rire du voyageur à la Renaissance (pp. 195-217); Jean BALSAMO, Les rires de Montaigne (pp. 219-232); Sylvie DESWARTE-ROSA, Les facéties de Zoroastro (pp. 235-256); Annie CCEURDEVEY, Roland de Lassus, ou l'invention de l'humour en musique (pp. 257-272); Jennifer BRITNELL, Le rire chez un «chaste et chrestien scripteur», Jean Bouchet (pp. 273-284); Anne-Pascale POUEY-MOUNOU, La Muse, vierge ou putain? (pp. 285-300); Stephen BAMFORTH, Grivoiserie et science chez Béroalde de Verville (pp. 301-324); Didier KAHN, Quelques parodies mordantes de l'alchimie (XVe-XVII siècles) (pp. 325-345); Elsa KAMMERER, Histoires des pantoufles. Rabelais, Lacroix, Nodier (pp. 347-363); Bruno ROY, Devinettes anciennes et pudeurs modernes. Les Demandes joyeuses en forme de quolibets (pp. 367-383); Richard COOPER, La guerre comique entre les Dames de Paris, de Lyon, de Rouen et de Milan (pp. 385-411); Chiara LASTRAIOLI, Le rire sans visage. Considérations autour de quelques ouvrages anonymes (pp. 413-426); Monique CHATENET, Montures pour rires (pp. 427-444).

3 Nelle sue conclusioni (Rire à la Renaissance: en quête de conclusion, pp. 447-510) Marie Madeleine FONTAINE offre un ampio studio che ricostruisce una teoria del rire rinascimentale, che non solo informa generi letterari propriamente detti, come la facetia di tradizione umanistica, ma viene concepito come attività globale, ad un tempo indipendente e necessariamente sociale. 